\title{
ECONOMÍA SOCIAL E IGUALDAD DE OPORTUNIDADES EN \\ EL ÁMBITO RURAL. UN ANÁLISIS APLICADO A LA COMUNIDAD AUTÓNOMA DE CASTILLA Y LEÓN
}

\author{
POR \\ Margarita RICO GONZÁLEZ \\ Jesús Mª́ GÓMEZ GARCÍA ${ }^{2}$
}

\section{RESUMEN}

Las desigualdades socioeconómicas por razón de sexo son mayores en las áreas rurales que en otros ámbitos más poblados. Sin embargo, se considera al colectivo de mujeres como un grupo prioritario para promover la activación económica de los territorios rurales, como así reconocen las distintas políticas públicas puestas en marcha para el desarrollo económico y social de esos espacios. Teniendo en cuenta esta apreciación, es posible establecer una relación estrecha entre los fines perseguidos por las políticas de igualdad de oportunidades y los valores y principios que preconizan las entidades que forman el sector de la economía social. En consecuencia, el objetivo de este trabajo se concreta en analizar la participación y situación laboral de las mujeres que se encuentran ocupadas en las empresas del sector de la economía social dentro del medio rural de Castilla y León, como forma organizativa generadora de empleos para este colectivo, bajo los principios de cooperación, solidaridad y equidad.

Palabras clave: Mujeres, Mercado Laboral, Desarrollo Rural, Empresas de Economía Social.

\footnotetext{
${ }^{1}$ Dpto. de Ingeniería Agrícola y Forestal. ETS de Ingenierías Agrarias. Universidad de Valladolid. Avda. Madrid 57. 34004 Palencia. Dirección de correo electrónico: mrico@iaf.uva.es

${ }^{2}$ Dpto. de Economía Aplicada. Facultad de CC Económicas y Empresariales. Universidad de Valladolid. Avda. Valle Esgueva, 6. 47011 Valladolid. Dirección de correo electrónico: jmgomez@eco.uva.es
}

REVESCO Nº 105 - MONOGRÁFICO: La economía social y la igualdad de género -

ISSN: 1885-8031 - www.ucm.es/info/revesco

DOI: 10.5209/rev_REVE.2011.v105.4

Fecha de recepción: 21/10/2010

Fecha de aceptación: 01/03/2011 
Claves ECONLIT: J160, M140, O180, P130.

\title{
SOCIAL ECONOMY AND EQUAL OPPORTUNITIES IN RURAL AREAS. AN ANALYSIS APPLIED TO AUTONOMOUS REGION OF CASTILLA AND LEÓN
}

\begin{abstract}
Socioeconomic inequalities based on sex are higher in rural areas than in other type of areas more populated. However, women are considered as a priority group of people to turn on the economy of rural areas, as it is well recognized in all the policies applied to those territories in favour of their social and economic development. Taking this consideration into account, it is possible to find out a close relationship between the goals pursued by the policies of equal opportunity, on one hand, and the values and principles advocated by the social economy organizations, on the other. The aim of this paper is to analyze the labour participation and current situation of women who are engaged in the firms of the social economy sector within the rural areas of Castilla and Leon, as a particular type of organizations which generates employment for this group of people considering the principles of cooperation, solidarity and equity.
\end{abstract}

Keywords: Women, Labour Market, Rural Development, Social Economy Firms.

\section{INTRODUCCIÓN}

El objetivo de la igualdad de oportunidades constituye, hoy en día, una prioridad transversal en los ordenamientos jurídicos de la mayor parte de los países. Sin embargo, a pesar de la creciente legislación y de los programas y actuaciones públicas aplicadas en las últimas décadas para tratar de corregir las desigualdades existentes entre hombres y mujeres a distintos niveles (internacional, nacional y regional), aún persisten importantes diferencias por razón de sexo en el ámbito económico y en el social. Estas disparidades resultan ser

REVESCO No 105 - MONOGRÁFICO: La economía social y la igualdad de género -

ISSN: 1885-8031 - www.ucm.es/info/revesco 
particularmente relevantes dentro del mercado de trabajo ${ }^{3}$, por lo que muchas de las acciones instrumentadas para tratar de eliminarlas o mitigarlas se han centrado, especialmente, en actuar en el ámbito laboral.

Se ha constatado que estas diferencias por razón de sexo se acrecientan dentro del ámbito rural, por cuanto las mujeres sufren aquí la doble marginación de ser mujer y de vivir en una zona rural (García Sanz, 2004; Langreo y Benito, 2005; Rico y Franco, 2009). Así, en los pequeños municipios se registran las tasas de actividad femeninas más bajas, inferiores a las de los hombres y también a las de las propias mujeres que viven en espacios más poblados ${ }^{4}$. El envejecimiento demográfico, la insuficiencia (o inexistencia) de servicios que permiten compatibilizar la esfera productiva y la reproductiva o la propia estrechez de los mercados de trabajo rurales se encuentran entre los principales factores que explican esta situación de mayor desigualdad. Paralelamente, las mujeres de estas zonas presentan mayor grado de eventualidad laboral y de trabajo a tiempo parcial que los varones y que las mujeres de zonas urbanas (Rico y Gómez-Limón, 2010). No en vano, la legislación existente sobre igualdad de oportunidades hace mención específica al colectivo de mujeres que habita en las zonas rurales, dadas sus especiales dificultades y necesidades. Precisamente para tratar de lograr la integración de las mujeres rurales en el mercado laboral y de proporcionar los servicios necesarios para su desarrollo vital, objetivo que se encuentra implícito en el artículo 30 de la Ley estatal de Igualdad (Ley 3/2007), el Ministerio de Agricultura, Pesca y Alimentación aprobó, en 2007, el Plan para favorecer la Igualdad entre Mujeres y Hombres en el Medio Rural, en el que se propone una batería de instrumentos y actuaciones que abarcan distintas esferas de la realidad socioeconómica: la educación y la formación, el mercado de trabajo, la salud, la participación en la vida política, etc.

En este contexto, una de las acciones propuestas en los diversos planes de igualdad es la potenciación de la economía social como fuente de creación de renta y empleo,

\footnotetext{
${ }^{3}$ Efectivamente, la creciente incorporación de la mujer al ámbito laboral se ha visto acompañada de hechos tales como la percepción de inferiores retribuciones en comparación con los varones en idénticos puestos de trabajo, la existencia de mayores tasas de desempleo, la mayor carga de trabajo reproductivo o la menor presencia en cargos de responsabilidad de las mujeres dentro de las empresas (Castaño, 2004; Garrido et al., 2006; de Cabo y Garzón, 2007).

${ }^{4}$ Según los datos del Censo de Población de 2001, la tasa de actividad de las mujeres que viven en los municipios españoles de menos de 2.000 habitantes es del 32,79\%, mientras que las de los varones de esos mismos espacios es del $60,11 \%$, siendo la media nacional femenina del $43,31 \%$.
}

REVESCO No 105 - MONOGRÁFICO: La economía social y la igualdad de género -

ISSN: 1885-8031 - www.ucm.es/info/revesco 
especialmente relevante para el colectivo de mujeres. Y ello, porque el sector de economía social, en cuanto que engloba un conjunto de entidades que están basadas en la asociación libre de personas y fundamentadas en la asunción de valores democráticos, participativos y solidarios ${ }^{5}$, tiende a favorecer la consecución del objetivo de igualdad de oportunidades en la sociedad (Chaves et al., 2005; Ribas, 2005). El fomento de la economía social se configura, consecuentemente, como una vía eficaz para favorecer la integración al mercado de trabajo de las mujeres bajo los principios de igualdad, solidaridad y cooperación (Sánchez, 2007). Pero la potenciación de este sector puede resultar aún más relevante para promover la integración de las mujeres de las áreas rurales (Salinas y Herranz, 2007; Bel, 2007), dadas las características socioeconómicas de esas zonas. Tal es así, que el emprendimiento femenino en el ámbito de la economía social puede representar una fórmula eficaz para contribuir a la empleabilidad de estas mujeres, sobre todo ante los nuevos yacimientos de empleo en los que este colectivo de personas tiene opciones laborales, a la par que favorece un mayor grado de vertebración territorial y de dinamismo socioeconómico en estas zonas (Gómez y Román, 2007; Puentes y Velasco, 2009; Melián y Campos, 2010).

Dadas estas consideraciones, el objetivo de este trabajo es doble. Por un lado, identificar las posibles relaciones existentes entre las medidas de acción pública contenidas en las distintas estrategias aplicadas a favor de la igualdad de oportunidades en el marco laboral, con especial interés en aquéllas cuyo ámbito de actuación sea el medio rural, y los postulados o valores que promueve la economía social. Por otro, analizar la participación laboral de las mujeres en las empresas de economía social del medio rural, para tratar de constatar si las desigualdades entre hombres y mujeres que se observan en el mercado laboral del conjunto de la economía también se reproducen, o no, dentro del sector de la economía social.

Como caso de estudio se analizará la Comunidad Autónoma de Castilla y León, que constituye una de las regiones españolas que en mayor medida manifiesta la especial situación del medio rural, caracterizada por la progresiva despoblación, el envejecimiento, la masculinización y el deterioro del tejido socioeconómico de los municipios rurales. Este análisis permitirá un mejor conocimiento del grado de participación del colectivo de mujeres

\footnotetext{
${ }^{5}$ Un análisis más profundo de la delimitación conceptual de la economía social se recoge en Chaves y Monzón (2001, 2008), Barea y Monzón (2002) y Monzón (2006), entre otros.
}

REVESCO No 105 - MONOGRÁFICO: La economía social y la igualdad de género -

ISSN: $1885-8031$ - www.ucm.es/info/revesco 
que habita en el medio rural en el ámbito de las entidades de economía social en su subsector empresarial o de mercado. Y, desde esta perspectiva, servirá como referencia en las actuaciones de los decisores públicos a la hora de establecer medidas de apoyo al empleo femenino en las zonas rurales, máxime si se tiene en cuenta la práctica inexistencia de estudios centrados en analizar bajo una óptica común la interrelación entre la desigualdad de género, el medio rural y la economía social.

Tras este primer apartado de contenido introductorio, se expone la metodología seguida para tratar de alcanzar los objetivos anteriormente señalados. A continuación, se procederá a identificar las interrelaciones existentes entre los criterios fundamentales que guían las políticas de igualdad de oportunidades y los principios o valores que subyacen en las entidades de economía social. Posteriormente, se pondrán de relieve los principales rasgos que caracterizan a la participación femenina en las empresas de economía social de las zonas rurales de Castilla y León. Finalmente, se exponen las principales conclusiones que se extraen de los resultados obtenidos en el análisis desarrollado.

\section{METODOLOGÍA}

La metodología empleada en este estudio tiene naturaleza cualitativa y cuantitativa. En el primer caso, desde el punto de vista cualitativo, se ha procedido a realizar una revisión normativa de las principales políticas de igualdad de oportunidades que actualmente se están instrumentando, ya sean supranacionales, nacionales o regionales, con el fin de llegar a identificar las posibles interrelaciones entre los principios y valores de la economía social y los criterios y objetivos de los planes y estrategias de igualdad de oportunidades.

En el segundo, se ha empleado una metodología cuantitativa para analizar la participación de las mujeres rurales de Castilla y León en las actividades de economía social en su vertiente empresarial y que ha consistido en el análisis estadístico de datos primarios extraídos de la realización de una encuesta propia a este tipo de empresas en la región, cuyos

REVESCO No 105 - MONOGRÁFICO: La economía social y la igualdad de género -

ISSN: 1885-8031 - www.ucm.es/info/revesco 
resultados globales se exponen en Fernández y Gómez (2007) ${ }^{6}$. Dicha encuesta considera tres tipos de empresas de economía social: cooperativas, en sus diferentes clases (agrarias, de trabajo, de explotación comunitaria de la tierra y/o del ganado, de consumidores y usuarios, de enseñanza, de transportistas, de servicios, de vivienda y de crédito), sociedades laborales y centros especiales de empleo. Para ello, se elaboró un directorio inicial a partir de informaciones de los registros oficiales de la Comunidad Autónoma, así como de los registros de algunas asociaciones sectoriales. Tras unificar ambas bases de datos y de depurar los resultados, se obtuvo una población final de 2.652 empresas a encuestar. Si bien el cuestionario de la encuesta cubría un amplio abanico de características de las empresas de economía social, en este trabajo solo se han utilizado los datos referidos a su estructura societaria y laboral, desagregados según el sexo. El trabajo de campo se realizó telefónicamente entre los meses de junio y julio de 2006, respondiendo un total de 1.191 empresas. La ficha técnica de la encuesta se presenta en la Tabla 1.

Tabla 1: Ficha técnica de la encuesta

\begin{tabular}{|l|l|}
\hline Universo estimado & $\begin{array}{l}3.000 \text { empresas de la economía social en la Comunidad Autónoma de } \\
\text { Castilla y León }\end{array}$ \\
\hline Tipo de muestreo & $\begin{array}{l}\text { Muestreo exhaustivo sobre } 2.652 \text { empresas de economía social existentes } \\
\text { en Castilla y León }\end{array}$ \\
\hline Tamaño muestral & 1.191 encuestas \\
\hline Margen de error & $\begin{array}{l}+/-2,25 \% \text { para datos globales en condiciones normales de muestreo } \\
(\mathrm{p}=\mathrm{q}=0,5,2 \square), \text { nivel de confianza del 95,5\% }\end{array}$ \\
\hline
\end{tabular}

Adicionalmente, para determinar el grado de participación laboral de las mujeres de las zonas rurales en el sector de la economía social, los resultados obtenidos en la encuesta según el sexo de la persona se han tenido que filtrar teniendo también en cuenta el tamaño del municipio donde se encuentra el domicilio social de la empresa. En este sentido, cabe señalar que el análisis se ha realizado discriminando entre los municipios de menos de 2.000 habitantes y los municipios de 2.000 a 10.000 habitantes. Asimismo, se ofrece el dato global para el conjunto de la región para permitir las convenientes comparaciones entre distintos ámbitos territoriales.

\footnotetext{
${ }^{6}$ Las fuentes estadísticas acerca del sector de la economía social en Castilla y León son muy escasas y meramente describen la distribución de las empresas por tipología y localización geográfica. Esta dificultad se magnifica si, además, se demandan datos municipales y diferenciados por sexo. Así, mediante la realización de encuestas ad hoc pueden obtenerse datos que no proporcionan las fuentes estadísticas registrales habituales.
}

REVESCO No 105 - MONOGRÁFICO: La economía social y la igualdad de género -

ISSN: $1885-8031$ - www.ucm.es/info/revesco 


\section{LAS POLÍTICAS DE IGUALDAD DE OPORTUNIDADES Y LA ECONOMÍA SOCIAL}

Según la Comisión Científica del CIRIEC-España (Barea y Monzón, 2002), dentro del ámbito de la economía social cabe diferenciar dos sectores: el sector empresarial o de mercado, cuyo objetivo principal es la venta de bienes y servicios en el mercado; y el sector de no mercado, que incluye a las entidades sin fines de lucro que desarrollan una actividad productiva y no distribuyen beneficios, obteniendo sus recursos de aportaciones voluntarias, de la administración pública y de rentas de la propiedad.

Paralelamente, se ha constatado que las entidades de economía social, en su conjunto, propugnan la decisión democrática, la distribución basada en la primacía de las personas y del trabajo frente al capital y la consecución de objetivos sociales distintos del lucro (Barea y Monzón, 2002; Fernández et al., 2010). Y, por ello, se trata de un sector que contribuye sobremanera al cumplimiento de una serie de funciones económicas que contribuyen a la construcción de una sociedad más plural, participativa, democrática y solidaria. En este sentido, también se ha señalado la existencia de una estrecha relación entre los fines perseguidos por las políticas de igualdad de oportunidades y los valores o principios rectores que se propugnan en el sector de la economía social (Serra, 2004).

Al objeto de tratar de determinar dichas interrelaciones, se revisan las políticas de igualdad de la Unión Europea, del Estado español y de la Comunidad Autónoma de Castilla y León, plasmadas en los denominados planes de igualdad de oportunidades, tratando de identificar las referencias que, directa o indirectamente, aluden a la economía social como un sector que favorece la creación de empleo femenino y que apoya y/o facilita su integración laboral, haciendo especial énfasis en el colectivo de mujeres que reside en el mundo rural.

\subsection{Unión Europea. Plan de Trabajo para la Igualdad entre las mujeres y los hombres (2006-2010)}

El vigente plan de igualdad de oportunidades de la UE para el periodo 2006-2010 se denomina "Plan de Trabajo para la Igualdad entre las mujeres y los hombres" y nace como

REVESCO No 105 - MONOGRÁFICO: La economía social y la igualdad de género -

ISSN: 1885-8031 - www.ucm.es/info/revesco 
continuidad a la exigua tarea que la Unión está llevando a cabo en pro de la igualdad entre géneros desde la década de los 70 en todas las esferas de la vida socioeconómica. Este Plan consta de dos partes: la primera la dedica a describir las áreas prioritarias de actuación a favor de la igualdad de oportunidades y la segunda se refiere a cómo mejorar la gobernanza a favor de la igualdad de género. A continuación, en la Tabla 2, se procede a resumir los distintos ámbitos y acciones que la UE propone para alcanzar una mayor igualdad entre los sexos.

Tabla 2: Áreas prioritarias de actuación del Plan de Igualdad. Unión Europea

\begin{tabular}{|c|c|}
\hline ÁREAS & OBJETIVOS \\
\hline $\begin{array}{l}\text { 1. Conseguir la misma independencia } \\
\text { económica para las mujeres y los } \\
\text { hombres }\end{array}$ & $\begin{array}{l}\text { - Alcanzar los objetivos de empleo de Lisboa. } \\
\text { - Eliminar la diferencia salarial entre las mujeres y los hombres. } \\
\text { - Aumentar la creación de empresas por parte de las mujeres. } \\
\text { - Garantizar la igualdad de género en la protección social y en la lucha } \\
\text { contra la pobreza. } \\
\text { - Reconocer la dimensión de género en el ámbito sanitario. } \\
\text { - Combatir la discriminación múltiple, sobre todo contra las mujeres } \\
\text { inmigrantes o de minorías étnicas. }\end{array}$ \\
\hline $\begin{array}{l}\text { 2. Conciliar la actividad laboral con la } \\
\text { vida privada y familiar }\end{array}$ & $\begin{array}{l}\text { - Alcanzar acuerdos laborales flexibles tanto para mujeres como para } \\
\text { hombres. } \\
\text { - Aumentar los servicios de asistencia. } \\
\text { - Mejorar políticas de conciliación tanto para mujeres como para hombres. }\end{array}$ \\
\hline $\begin{array}{l}\text { 3. Promover la representación paritaria de } \\
\text { mujeres y hombres en la toma de } \\
\text { decisiones }\end{array}$ & $\begin{array}{l}\text { - Fomentar la participación de las mujeres en la política. } \\
\text { - Fomentar la participación de las mujeres en la toma de decisiones. } \\
\text { - Favorecer la presencia de las mujeres en la ciencia y la tecnología. }\end{array}$ \\
\hline $\begin{array}{l}\text { 4. Erradicar la violencia de género y la } \\
\text { trata de seres humanos }\end{array}$ & $\begin{array}{l}\text { - Erradicar la violencia de género. } \\
\text { - Eliminar la trata de seres humanos. }\end{array}$ \\
\hline $\begin{array}{l}\text { 5. Eliminar los estereotipos sexistas en la } \\
\text { sociedad }\end{array}$ & $\begin{array}{l}\text { - Eliminar los estereotipos sexistas en la educación, la formación y la } \\
\text { cultura. } \\
\text { - Eliminar los estereotipos sexistas en el mercado laboral. } \\
\text { - Eliminar los estereotipos sexistas en los medios de comunicación. }\end{array}$ \\
\hline $\begin{array}{l}\text { 6. Promover la igualdad de género fuera } \\
\text { de la UE }\end{array}$ & $\begin{array}{l}\text { - Aplicar la legislación de la UE en los países adherentes, los candidatos y } \\
\text { los candidatos potenciales. } \\
\text { - Promover la igualdad de género en la Política Europea de Vecindad } \\
\text { (PEV), la política exterior y la de desarrollo. }\end{array}$ \\
\hline
\end{tabular}

Atendiendo a las diversas áreas descritas en dicha Tabla, así como a los objetivos que se pretenden alcanzar genéricamente en cada una de ellas, cabe afirmar que todas ellas parecen mostrar una relación clara con los principios y valores de la economía social, por cuanto persiguen una situación más igualitaria y no discriminatoria entre sexos. Aunque en el Plan no se hace una referencia expresa al sector de la economía social ni a su papel, cabe destacar algunas áreas y medidas propuestas que sí pueden tener una vinculación más directa en lo que representa el ámbito de la economía social, que se han sombreado en la Tabla para una mejor identificación.

- En primer lugar, dentro del área 1, referida a la consecución de independencia económica, se alude a la promoción de la actividad empresarial femenina como forma de aumentar el

REVESCO No 105 - MONOGRÁFICO: La economía social y la igualdad de género -

ISSN: 1885-8031 - www.ucm.es/info/revesco 
empleo de este colectivo. Para ello, la Comisión propone acciones relacionadas con el impulso de iniciativas de responsabilidad social de las empresas en favor de la igualdad de género.

- Asimismo, en el área 2, relativa a la conciliación de la actividad laboral y familiar, subyace el reto de las entidades de economía social consistente en la participación igualitaria en el mercado laboral tanto de varones como de mujeres y del reparto equitativo de las responsabilidades domésticas y familiares. El objetivo que hace mención a aumentar los servicios de asistencia a las personas es de particular importancia para el caso femenino, ya que una gran parte de las cooperativas y sociedades laborales en las que participan mayoritariamente mujeres se ocupa precisamente de desarrollar este tipo de servicios de atención a la población.

- En cuanto al área 3, centrada en la participación política y social, sus objetivos hacen clara alusión a los principios y valores de la economía social, basados en la democracia y la participación igualitaria de todos los individuos, sin distinción de raza, etnia o sexo.

- Finalmente, en lo que se refiere al área 5, que aborda la eliminación de los estereotipos sexistas, se vuelve a ahondar en la necesidad de alcanzar una participación igualitaria en los distintos puestos de trabajo y eliminar la tradicional segregación entre empleos femeninos y masculinos.

\subsection{Estado español. Plan Estratégico de Igualdad de Oportunidades 2008-2011}

En el ámbito nacional, la Ley 3/2007 de Igualdad propone publicar periódicamente las pautas a seguir en dicha materia a través de la elaboración de planes de igualdad, que contengan los objetivos perseguidos y las acciones a implementar en las diversas áreas de actuación. Más concretamente, el Plan de igualdad elaborado por el Estado español para el periodo 2008-2011 es el quinto temporalmente hablando y se basa en los principios de igualdad y no discriminación. Está conformado por 12 ejes, en cada uno de los cuales se establece un marco teórico explicativo, un diagnóstico sobre la situación actual en España, los objetivos estratégicos y las propuestas de actuación. En la Tabla 3 aparecen esos ejes con sus correspondientes objetivos.

REVESCO No 105 - MONOGRÁFICO: La economía social y la igualdad de género -

ISSN: 1885-8031 - www.ucm.es/info/revesco 
Al igual que ocurre en el caso del Plan de igualdad de la UE, el Plan español está basado en los principios de igualdad, no discriminación, solidaridad y equidad, con lo que, en conjunto, compartiría plenamente los criterios y valores presentes en el sector de la economía social. No obstante, cabe proceder a identificar aquellos objetivos y medidas de actuación que, a nuestro juicio, estarían más relacionados con dicho sector. Se trata, en concreto, de las siguientes:

- El área de participación política y social alude a la necesidad de aumentar la participación femenina en puestos de responsabilidad en todos los órganos económicos, políticos y sociales que rigen la organización de la sociedad.

- Por su parte, en el área de participación económica, uno de los objetivos se refiere a realizar acciones de responsabilidad social en las empresas, con el fin de que éstas conjuguen las dimensiones económica, social y ambiental que les afectan y elaboren un plan de objetivos a alcanzar atendiendo a dichos ámbitos.

- Dentro de esa misma área, otro de los objetivos alude a la necesidad de favorecer y fomentar el empresariado femenino. Una de las medidas a desarrollar se basa en el apoyo del asociacionismo de las mujeres empresarias y la generación de redes, facilitando su participación social.

- En cuanto al área de corresponsabilidad, se hace referencia a la necesidad de que se promueva un modelo de convivencia más igualitaria, tanto dentro de la familia como en el mercado laboral y en el resto de estructuras sociales, para lo que se demanda fortalecer plenamente la red de servicios de atención y cuidado a menores y personas dependientes, facilitando servicios flexibles, adaptados a las necesidades de las personas y a situaciones de difícil cobertura.

- El área de educación también se relaciona indirectamente con el fomento de la economía social, en tanto en cuanto preconiza la necesidad de diseñar planes de estudios no sexistas y plantea introducir medidas de conciliación en los centros de trabajo educativos.

- En el área de atención a la diversidad e inclusión social se apunta la necesidad de apoyar la incorporación en igualdad de colectivos de mujeres desfavorecidas dentro de todas las esferas de la sociedad, incluido el ámbito laboral.

REVESCO No 105 - MONOGRÁFICO: La economía social y la igualdad de género -

ISSN: 1885-8031 - www.ucm.es/info/revesco 
Tabla 3: Ejes de actuación del Plan de Igualdad. Estado español

\begin{tabular}{|c|c|}
\hline ÁREAS & OBJETIVOS \\
\hline $\begin{array}{c}\text { 1. Participación política } \\
\text { y social }\end{array}$ & $\begin{array}{l}\text { - Aumentar la participación de las mujeres en los puestos de representación y decisión política para alcanzar una composición equilibrada entre mujeres y hombres. } \\
\text { - Incrementar la participación de las mujeres en los puestos de representación y dirección de la Administración del Estado. } \\
\text { - Incrementar la participación de las mujeres en los puestos de dirección y responsabilidad en el poder judicial. } \\
\text { - Incrementar la participación de las mujeres en la dirección de las empresas. } \\
\text { - Incrementar la participación de las mujeres en los puestos de dirección y responsabilidad en los medios de comunicación. } \\
\text { - Remover los obstáculos que impiden la participación de las mujeres. } \\
\text { - Implementación de las Unidades de Igualdad en los Ministerios. } \\
\text { - Promoción de la labor desarrollada por los Observatorios de Igualdad. }\end{array}$ \\
\hline $\begin{array}{l}\text { 2. Participación } \\
\text { económica }\end{array}$ & $\begin{array}{l}\text { - Fomentar la empleabilidad, la calidad en el empleo y la igualdad salarial de las mujeres. } \\
\text { - Velar por la igualdad de oportunidades entre mujeres y hombres y fomentar las acciones de responsabilidad social en las empresas. } \\
\text { - Promover el emprendimiento y empoderamiento económico femenino. } \\
\text { - Analizar y medir la participación económica de mujeres y hombres: hacia la igualdad en femenino. }\end{array}$ \\
\hline 3. Corresponsabilidad & $\begin{array}{l}\text { - El ámbito privado/doméstico. Promover el desarrollo de un modelo de convivencia familiar y social más igualitaria. } \\
\text { - Promover el desarrollo de un nuevo modelo de relaciones laborales y empleo de calidad que facilite la corresponsabilidad para la conciliación de la vida personal y laboral. } \\
\text { - Los servicios públicos. Fortalecer y desarrollar, plenamente, la red de servicios de atención y cuidado a menores y personas dependientes. } \\
\text { - Propiciar un cambio en el diseño y funcionamiento de las infraestructuras urbanas dirigido a facilitar la conciliación de los diferentes tiempos de mujeres y hombres. }\end{array}$ \\
\hline 4. Educación & $\begin{array}{l}\text { - Promover que el profesorado y quienes trabajan en la enseñanza reciban la formación adecuada, tanto inicial como continua, en coeducación, prevención de violencia de género, e } \\
\text { igualdad de oportunidades entre hombres y mujeres. } \\
\text { - Promover la presencia equilibrada de mujeres y hombres en los órganos dirección, participación y toma de decisiones del sistema educativo. } \\
\text { - Implementar la coeducación en los proyectos educativos de centro. } \\
\text { - Prevenir y actuar contra la violencia de género en todos los tramos de la educación. } \\
\text { - Potenciar la integración de la perspectiva de género en las actividades deportivas. } \\
\text { - Promover que los libros de texto y los materiales educativos se editen respondiendo a criterios de igualdad y no discriminación, incorporando la visión y las aportaciones } \\
\text { realizadas por las mujeres en todos los contenidos escolares y académicos. } \\
\text { - Promover la inclusión de contenidos y actividades específicas, adaptados a cada tramo educativo, sobre el significado y alcance de la igualdad entre mujeres y hombres. } \\
\text { - En el marco de la atención a la diversidad, prestar una atención específica a los colectivos de niñas y mujeres que se encuentren en situación de mayor vulnerabilidad por sufrir } \\
\text { una doble discriminación por su situación de discapacidad, pertenencia a minorías étnicas, migración o exclusión social. } \\
\text { - Desde el marco de los principios democráticos de la Constitución y la Declaración Universal de los Derechos Humanos, y teniendo en cuenta la creciente diversidad cultural del } \\
\text { alumnado, garantizar una educación para la igualdad y desde la igualdad entre hombres y mujeres. } \\
\text { - Adaptar los programas de educación de personas adultas a los nuevos perfiles y necesidades de los destinatarios. } \\
\text { - Fomentar el diseño y realización de programas de orientación no sexista que promuevan la elección de estudios de forma no discriminatoria. } \\
\text { - Promover la gestión de los centros educativos con criterios de conciliación de la vida laboral y personal. } \\
\text { - Incorporar la perspectiva de género en los procesos de evaluación del sistema educativo. }\end{array}$ \\
\hline 5. Innovación & $\begin{array}{l}\text { - Incorporar la transversalidad de género como principio rector de las políticas desarrolladas en el ámbito de la innovación tecnológica y la SI. } \\
\text { - Ampliar el conocimiento, actualmente disponible, sobre la participación femenina en los entornos de la ciencia y la tecnología, así como acerca de la brecha digital de género, a } \\
\text { fin de alimentar estrategias innovadoras para alcanzar la igualdad, también, en estos ámbitos. } \\
\text { - Asumir, por parte de las Administraciones Públicas, el liderazgo para incorporar a las mujeres como protagonistas, con acciones que faciliten su participación en los ámbitos } \\
\text { tecnológicos, la adquisición de las capacidades necesarias (fluidez tecnológica) y la inclusión de grupos vulnerables. } \\
\text { - Integrar la visión de las mujeres en los procesos de diseño, producción y gestión de ámbitos científicos (equidad tecnológica). } \\
\text { - Diseñar acciones dirigidas a que Internet se convierta en un ámbito de libertad que favorezca la expansión de los proyectos de las mujeres, estableciéndose como herramienta para } \\
\text { cambiar los estereotipos y las relaciones de género. }\end{array}$ \\
\hline
\end{tabular}

REVESCO No 105 - MONOGRÁFICO: La economía social y la igualdad de género -

ISSN: 1885-8031 - www.ucm.es/info/revesco 


\begin{tabular}{|c|c|}
\hline 6. Conocimiento & $\begin{array}{l}\text { - Formalizar los Estudios Feministas, de las Mujeres y del Género en el ámbito universitario. } \\
\text { - Incrementar el número de mujeres en la generación del conocimiento. } \\
\text { - Fomentar el conocimiento desde la perspectiva feminista, del género. } \\
\text { - Recuperar la memoria histórica de las mujeres. } \\
\text { - Impulsar la igualdad de oportunidades en la Universidad. } \\
\text { - Visibilizar y apoyar las aportaciones de las mujeres jóvenes en la Universidad. }\end{array}$ \\
\hline 7. Salud & $\begin{array}{l}\text { - Promover la producción, publicación y difusión de información cualitativa y cuantitativa sobre la influencia del género en la salud y la atención de la salud. } \\
\text { - Promover la aplicación de la transversalidad de género a las políticas de salud, así como impulsar políticas específicas de salud de las mujeres. } \\
\text { - Contribuir a mejorar aspectos específicos de la salud de las mujeres, así como incidir en enfermedades de alta prevalencia, o sensibles al impacto de género. } \\
\text { - Impulsar la participación y empoderamiento de las mujeres en los procesos de salud. }\end{array}$ \\
\hline 8. Imagen & $\begin{array}{l}\text { - Mostrar a las mujeres y "lo femenino" como sujetos activos en la construcción social. } \\
\text { - Contribuir a la difusión de imágenes no sexistas en los medios de comunicación y la publicidad. } \\
\text { - Promover modelos igualitarios en los que se vean implicados los principales agentes sociales (medios de comunicación, educación, grupo de iguales, medio familiar,...). } \\
\text { - Vigilar que la Corporación RTVE y la agencia EFE, así como los entes audiovisuales públicos de las Comunidades Autónomas, persigan, en su programación, los objetivos } \\
\text { incluidos en los artículos } 37 \text { y } 38 \text { de la LOIEMH. } \\
\text { - Vigilar que los medios de titularidad privada persigan, en su programación, los objetivos planteados en el artículo } 39 \text { de la LOIEMH. }\end{array}$ \\
\hline $\begin{array}{l}\text { 9. Atención a la } \\
\text { diversidad e inclusión } \\
\text { social }\end{array}$ & $\begin{array}{l}\text { - Incorporar la perspectiva de género y la gestión de la diversidad en la oferta de servicios, atención y seguimiento de las entidades públicas de salud, educación, empleo, justicia, } \\
\text { seguridad y vivienda. } \\
\text { - Liderar, por parte de los poderes públicos, las políticas, para la inclusión de las mujeres en situación o riesgo de exclusión social. } \\
\text { - Diseñar estrategias con perspectiva de género de colaboración, supervisión y acompañamiento de los programas que se realizan desde el tercer sector, para la inclusión de las } \\
\text { mujeres en situación o riesgo de exclusión social. } \\
\text { - Impulsar el conocimiento de los procesos de exclusión y pobreza de las mujeres. } \\
\text { - Adecuar la respuesta y recursos de los Servicios Sociales a las diferentes necesidades de los colectivos de mujeres en situación o riesgo de exclusión. }\end{array}$ \\
\hline 10. Violencia & $\begin{array}{l}\text { - Promover el conocimiento del fenómeno, así como la publicación y difusión de los estudios realizados. } \\
\text { - Fortalecer las medidas de sensibilización y prevención de la violencia de género e incrementar el grado de implicación de la sociedad para combatirla desde un mejor } \\
\text { conocimiento de las causas y consecuencias de este fenómeno violento. } \\
\text { - Mejorar la atención integral a las mujeres víctimas de la violencia de género. } \\
\text { - Reforzar la protección policial y judicial de las víctimas de la violencia de género. } \\
\text { - Intensificar la formación y especialización de profesionales que intervienen en las situaciones de violencia de género. } \\
\text { - Promover y consolidar procedimientos de coordinación intra e interinstitucionales para garantizar una mayor eficacia de la respuesta frente a las situaciones de violencia de } \\
\text { género. } \\
\text { - Afianzar el seguimiento y evaluación continua de las medidas puestas en marcha en la lucha contra la violencia de género, con el fin de determinar la eficacia de la respuesta y su } \\
\text { impacto en la evolución del fenómeno violento. }\end{array}$ \\
\hline $\begin{array}{l}\text { 11. Política exterior y de } \\
\text { cooperación para el } \\
\text { desarrollo }\end{array}$ & $\begin{array}{l}\text { - Garantizar la aplicación de la transversalidad de género y la igualdad entre hombres y mujeres en la política exterior española. } \\
\text { - Promover y reforzar la integración del enfoque de género en el desarrollo y el empoderamiento de las mujeres en la política de cooperación para el desarrollo española, como } \\
\text { forma de contribuir a la plena ciudadanía de las mujeres, como requisito para el desarrollo y la paz. } \\
\text { - Garantizar la aplicación de la transversalidad de la perspectiva de género en las políticas públicas sobre migraciones y desarrollo. }\end{array}$ \\
\hline $\begin{array}{l}\text { 12. Tutela del derecho a } \\
\text { la igualdad }\end{array}$ & $\begin{array}{l}\text { - Promover el conocimiento de las situaciones de discriminación por razón de sexo. } \\
\text { - Reforzar el asesoramiento de las mujeres víctimas de discriminación por razón de sexo. } \\
\text { - Especialización de las y los operadores jurídicos para la aplicación del derecho a la igualdad. } \\
\text { - Promover la especialización en materia de igualdad de los agentes sociales y organizaciones de mujeres cuyo fin primordial sea la igualdad entre mujeres y hombres. } \\
\text { - Reforzar la intervención de los organismos públicos con competencia en la materia para la defensa del derecho de igualdad de trato y oportunidades entre mujeres y hombres. }\end{array}$ \\
\hline
\end{tabular}

REVESCO No 105 - MONOGRÁFICO: La economía social y la igualdad de género -

ISSN: 1885-8031 - www.ucm.es/info/revesco 


\subsection{Estado español. Plan para favorecer la igualdad entre mujeres y hombres en el medio rural, 2007}

En el año 2007 el Ministerio de Agricultura, Pesca y Alimentación publica el Plan para favorecer la igualdad entre mujeres y hombres en el medio rural, atendiendo a la propuesta recogida en la Ley 3/2007 de Igualdad. Los principios rectores de este Plan son los de transversalidad y empoderamiento de las mujeres y el principal objetivo se centra en alcanzar la igualdad de oportunidades en el medio rural, evitando la doble discriminación de ser mujer y vivir en un ámbito rural (Ministerio de Agricultura, Pesca y Alimentación, 2007).

Las medidas propuestas en este Plan no están recogidas en áreas temáticas, como ocurre en otros planes de igualdad, sino que se agrupan en función del organismo público responsable de llevarlas a cabo. De acuerdo con ello, las referencias más claras al sector de la economía social se aprecian dentro del conjunto de acciones que desarrolla el propio Ministerio, dedicadas a promover el desarrollo rural. Así, se proponen medidas orientadas a incentivar una mayor participación de las mujeres en los consejos rectores y en los órganos técnicos de las cooperativas. Asimismo, se prevé el fomento de la integración cooperativa de ámbito estatal de las entidades asociativas agrarias, para facilitar la cooperación interterritorial y la economía en red. Además, se propone prestar apoyo a las asociaciones de mujeres integradas en las organizaciones profesionales agrarias.

Por otro lado, el Plan señala que dentro de las políticas generales destinadas a las zonas rurales, el principio de igualdad de oportunidades se considera fundamental y todas ellas han de poner en marcha medidas específicas dirigidas a las mujeres. Cabe señalar, a modo de ejemplo, que dentro de las acciones contenidas en la Ley de Desarrollo Sostenible del Medio Rural (Ley 45/2007) se propone el apoyo expreso al autoempleo y al empleo en cooperativas, sobre todo en sectores de actividad relacionados con el uso de nuevas tecnologías.

REVESCO No 105 - MONOGRÁFICO: La economía social y la igualdad de género -

ISSN: 1885-8031 - www.ucm.es/info/revesco 
3.4. Comunidad Autónoma de Castilla y León. IV Plan de Igualdad entre mujeres y hombres 2007-2011

La Comunidad de Castilla y León tampoco ha sido ajena a la elaboración de normativa específicamente diseñada para superar las diferencias socioeconómicas existentes por razón de género y desde el año 1994 ha elaborado cuatro planes de igualdad. El último de ellos abarca el periodo 2007-2011 y desarrolla 7 áreas que se hacen operativas por medio de 23 objetivos específicos y que se concretan instrumentalmente en 219 medidas (Tabla 4).

REVESCO No 105 - MONOGRÁFICO: La economía social y la igualdad de género -

ISSN: 1885-8031 - www.ucm.es/info/revesco 
Tabla 4: Áreas de intervención del Plan de Igualdad. Castilla y León

\begin{tabular}{|c|c|}
\hline ÁREAS & OBJETIVOS \\
\hline 1. Transversalidad & $\begin{array}{l}\text { - Mostrar explícitamente el compromiso de la Junta de Castilla y León con la igualdad entre mujeres y hombres, consolidando dicho principio en todas las } \\
\text { políticas regionales. } \\
\text { - Promover la cooperación entre Administraciones e instituciones en favor de la igualdad de oportunidades entre mujeres y hombres. } \\
\text { - Consolidar la perspectiva de género en la cooperación al desarrollo. }\end{array}$ \\
\hline 2. Empleo y formación & $\begin{array}{l}\text { - Formular y apoyar cambios o adecuaciones para eliminar las discriminaciones de género en el mercado de trabajo. } \\
\text { - Favorecer la plena inserción laboral de las mujeres, potenciando su iniciativa emprendedora y su capacidad de acceder al empleo por cuenta ajena. }\end{array}$ \\
\hline 3. Salud y calidad de vida & $\begin{array}{l}\text { - Visibilizar los problemas sanitarios específicos de las mujeres, impulsando la investigación y difusión de información sobre su salud. } \\
\text { - Sensibilizar y formar con perspectiva de género a los sectores involucrados en el cuidado de la salud, apoyando políticas y programas dirigidos a } \\
\text { mejorar la salud y el bienestar de las mujeres. } \\
\text { - Desarrollar una cultura de planificación urbanística y gestión medioambiental que tenga en cuenta las necesidades de las mujeres e impulse su } \\
\text { participación. }\end{array}$ \\
\hline $\begin{array}{l}\text { 4. Sensibilización, } \\
\text { educación y medios de } \\
\text { comunicación }\end{array}$ & $\begin{array}{l}\text { - Impulsar la construcción de una sociedad igualitaria para mujeres y hombres. } \\
\text { - Formar y sensibilizar a la comunidad educativa con perspectiva de género, consolidando programas, materiales y prácticas pedagógicas coeducativas. } \\
\text { - Promover una imagen real y no estereotipada de las mujeres en los medios de comunicación y la publicidad. }\end{array}$ \\
\hline $\begin{array}{l}\text { 5. Participación y acceso } \\
\text { al poder }\end{array}$ & $\begin{array}{l}\text { idar una opinión pública partidaria de la mayor participación y presencia de las mujeres en todos los ámbitos de la vida social. } \\
\text { tar el acceso de las mujeres a las estructuras de poder y a puestos de responsabilidad. }\end{array}$ \\
\hline $\begin{array}{l}\text { 6. Mujeres en el medio } \\
\text { rural }\end{array}$ & $\begin{array}{l}\text { - Apoyar y visibilizar la participación, el acceso al empleo y la mayor calidad de vida de las mujeres del medio rural. } \\
\text { - Sensibilizar en la necesidad de políticas en favor de la igualdad de oportunidades en el medio rural. }\end{array}$ \\
\hline $\begin{array}{l}\text { 7. Mujeres con } \\
\text { problemática específica }\end{array}$ & $\begin{array}{l}\text { - Mejorar las condiciones de vida de las mujeres que ejercen la prostitución, ofreciendo alternativas de inserción sociolaboral a quienes decidan } \\
\text { abandonar su ejercicio. } \\
\text { - Mejorar las condiciones de vida de las drogodependientes, favoreciendo su integración sociolaboral y su bienestar y apoyando procesos de } \\
\text { desintoxicación. } \\
\text { - Mejorar las condiciones de vida de las presas, minimizando las consecuencias negativas de la privación de libertad y favoreciendo su integración } \\
\text { sociolaboral y su bienestar. } \\
\text { - Conseguir la plena integración social de las mujeres inmigrantes, en condiciones de igualdad, en la sociedad castellana y leonesa. } \\
\text { - Conseguir la plena integración social de las discapacitadas, en condiciones de igualdad, en la sociedad castellana y leonesa. } \\
\text { - Conseguir la plena integración social de las mujeres de etnia gitana, en condiciones de igualdad, en la sociedad castellana y leonesa. } \\
\text { - Mejorar las condiciones de vida de las mujeres mayores, favoreciendo su bienestar. }\end{array}$ \\
\hline
\end{tabular}
Fuente: elaboración propia a partir de Junta de Castilla y León (2007).

REVESCO No 105 - MONOGRÁFICO: La economía social y la igualdad de género -

ISSN: 1885-8031 - www.ucm.es/info/revesco 
Nuevamente, destaca el hecho de que la práctica totalidad de los objetivos incluidos en este Plan comparten, esencialmente, los principios y valores de la economía social. Sin embargo, en el caso del plan regional, a diferencia del europeo y del nacional, sí se incluyen menciones directas y específicas a dicho sector, como se detalla a continuación.

- Dentro del área de empleo y formación, y en lo que concierne al objetivo de eliminar las discriminaciones por sexo en el mercado laboral, se insta a los agentes sociales (sindicatos y organizaciones empresariales) a colaborar en la tarea de velar por el cumplimiento de la igualdad en las empresas y a luchar contra situaciones de acoso sexual. También, se determina la necesidad de participación paritaria en los órganos de representación y en las mesas de negociación colectiva de las empresas. Asimismo, dentro de esta área, se hace una alusión directa al sector de la economía social, ya que se propone el apoyo a las organizaciones empresariales de mujeres profesionales de los distintos sectores, promocionando la realización de encuentros para la formulación de acciones conjuntas, con especial atención a las de economía social.

- En cuanto al segundo objetivo de esta área de empleo y formación (favorecer la inserción laboral femenina y el empresariado), se proponen medidas tendentes a incrementar la empleabilidad de las mujeres y especialmente a través del autoempleo y la creación de empresas, por medio de formación específica y de ayudas públicas de orientación y asesoramiento técnico.

- En el área de participación y acceso al poder se destaca la necesidad de que las mujeres participen en mayor grado en las organizaciones sindicales y empresariales para lograr una mayor representación en la toma de decisiones. Además, se pretende impulsar el acceso de las mujeres a cargos de responsabilidad en la Administración Regional y Local. Finalmente, en esta misma área también se alude a la necesidad de fomentar el movimiento asociativo de las mujeres de Castilla y León impulsando, entre otras medidas, programas formativos y encuentros entre tales asociaciones.

- Existe una mención específica al papel del sector de la economía social en el área de mujeres y medio rural. Así, se propone apoyar el asociacionismo de las mujeres del medio rural en todos los ámbitos, fomentando espacios, encuentros y programas para el intercambio de experiencias e iniciativas. Asimismo, se insta a aplicar medidas de acción positiva para favorecer la mayor participación de las mujeres en organizaciones políticas, empresariales, sindicales, profesionales y sociales del medio rural.

REVESCO No 105 - MONOGRÁFICO: La economía social y la igualdad de género -

ISSN: 1885-8031 - www.ucm.es/info/revesco 
- Siguiendo en el área de mujeres rurales, también se insta a afianzar el empleo y autoempleo femenino como instrumento para frenar la despoblación rural, para lo cual se propone aplicar medidas de fomento de los nuevos yacimientos de empleo, en los que las fórmulas de economía social tienen amplia experiencia y oportunidades.

- En el área de mujeres con problemática específica se propone facilitar la incorporación al mercado laboral a colectivos de mujeres en evidente riesgo o estado de exclusión social, como pueden ser las prostitutas, drogodependientes o reclusas.

\section{LA ECONOMÍA SOCIAL Y LA MUJER RURAL EN CASTILLA Y LEÓN}

Tradicionalmente, el aporte de trabajo de las mujeres en la explotación agraria familiar ha resultado invisible y carente de suficiente reconocimiento social y económico (Sampedro, 1996; Camarero, 2006). Sin embargo, no cabe duda de que el desarrollo de las tareas realizadas por estas mujeres ha sido esencial para el sostenimiento de la economía rural. La falta de este reconocimiento laboral, la dificultad de encontrar un empleo en otro tipo de actividades dentro de las zonas rurales o la progresiva decadencia social y económica de los pequeños pueblos han sido factores que han desencadenado el progresivo abandono del campo a partir de los años 50 del pasado siglo, principalmente por parte del colectivo femenino (Camarero y Sampedro, 2008; Rico y Franco, 2009). Las consecuencias de ese éxodo poblacional se reflejan en la actual estructura socioeconómica de la mayor parte de las áreas rurales del interior de España, caracterizadas por la despoblación, el envejecimiento y la masculinización y, consecuentemente, por el progresivo deterioro de sus bases económicas y sociales $^{7}$.

Esta decadencia socioeconómica de las zonas rurales reduce, aún más si cabe, las posibilidades de empleo de las mujeres que desarrollan su vida personal y profesional en un pequeño municipio. Sin embargo, hay un común acuerdo de que la recuperación del mundo rural depende en gran medida de las mujeres y del aprovechamiento de su mano de obra para emprender nuevas y diversificadas actividades que ayuden a sostener el sistema económico de

\footnotetext{
${ }^{7}$ Para una descripción pormenorizada de las características económicas y sociales del colectivo de mujeres que habitan en el medio rural de Castilla y León, puede consultarse CES de Castilla y León (2004) o Rico y Franco (2009).
}

REVESCO No 105 - MONOGRÁFICO: La economía social y la igualdad de género -

ISSN: 1885-8031 - www.ucm.es/info/revesco 
los pueblos (García Ramón y Baylina, 2000; Rico y Gómez, 2009). Existe evidencia empírica que demuestra que la explotación de los nuevos yacimientos de empleo puede suponer un revulsivo para todas aquellas zonas que aún posean un cierto nivel de población crítica para recuperar la dinámica del espacio rural (González Regidor, 2008; García Pascual, 2001). Las nuevas formas organizativas sociales y empresariales, entre las que se incluyen las pertenecientes al ámbito de la economía social, las ayudas desde el sector público y el esfuerzo de los propios habitantes de las zonas rurales son elementos que bien pueden contribuir a poner freno a procesos de despoblamiento y de decadencia de gran parte de los municipios rurales de Castilla y León.

\subsection{Estimación de la ocupación}

A continuación, se analiza la participación de las mujeres rurales de Castilla y León dentro de las entidades de economía social pertenecientes al sector empresarial o de mercado. Para ello, y tal y como se especificó en el apartado metodológico, se utilizarán los datos obtenidos en una encuesta realizada en el año 2006 a un gran número de empresas de economía social que operan en esta Comunidad Autónoma. Dado que los datos provienen de una encuesta y no de un registro, para calcular el empleo generado por el sector empresarial de la economía social en las zonas rurales de Castilla y León y diferenciarlo por sexos, es necesario realizar una estimación de la población ocupada. Siguiendo un procedimiento de cálculo análogo al expuesto en Fernández y Gómez (2007), los resultados obtenidos se muestran en la Tabla 5.

El primer dato a tener en cuenta es que de los 22.090 individuos que aproximadamente se encuentran ocupados en las empresas de economía social en Castilla y León en 2006 (socios trabajadores y empleados no socios), el 32,1\% son mujeres. A la luz de tal cifra, puede señalarse que en este tipo de empresas también se produce una desigual ocupación por razón de sexo. Además, el nivel de ocupación femenino respecto del masculino es inferior, incluso, al que se produce en el conjunto de la economía regional, donde, en ese mismo año, el 38,8\% del total de ocupados eran mujeres (según datos de la Encuesta de Población Activa).

REVESCO No 105 - MONOGRÁFICO: La economía social y la igualdad de género -

ISSN: 1885-8031 - www.ucm.es/info/revesco 
Si se realiza esa misma desagregación teniendo en cuenta el nivel de ruralidad del territorio se aprecia que, del total de trabajadores en empresas de economía social de los municipios más rurales, el 27,3\% son mujeres, una cifra casi 5 puntos por debajo de la media regional, mientras que, para el caso de las zonas rurales intermedias, la ocupación femenina es del 37,6\%, una proporción mayor que en los municipios más pequeños y que supera también la media regional. Por ello, y al igual que ocurre en la economía regional en su conjunto, la participación laboral de las mujeres de los municipios intermedios en empresas de economía social es proporcionalmente más activa que en el caso de los núcleos más rurales.

Comparando las anteriores cifras con los datos de ocupación del conjunto de la economía ofrecidos por el Censo de Población de $2001^{8}$, cabe resaltar que en el cómputo económico global el 30,3\% del total de ocupados en los municipios de menos de 10.000 habitantes son mujeres, mientras que ese porcentaje se eleva hasta el 31,7\% al referirnos exclusivamente a las empresas de economía social. Este resultado pone de manifiesto que la participación laboral de las mujeres en las empresas de economía social es sensiblemente superior a su participación en el conjunto de la economía rural, situación que favorece la empleabilidad de las mujeres. Pese a todo, persisten las diferencias entre la ocupación femenina y la masculina, debido a la aún escasa incorporación de la mujer al mercado laboral, si bien en los últimos años la evolución ha sido bastante favorable (Rico y Franco, 2009).

Diversos estudios (Ribas y Sajardo, 2004; Ribas, 2005) han puesto de manifiesto que las desigualdades laborales que afectan a las mujeres en el seno de la economía tradicional, y que también se reproducen dentro de las entidades de economía social, pueden ser explicadas a través de las teorías feministas y sociosexuales. Estas teorías sostienen, en esencia, que las asimetrías existentes entre hombres y mujeres en el contexto socioeconómico están condicionadas por la tradición cultural y religiosa, por las costumbres o por los roles y estereotipos dominantes en la sociedad y que describen pautas de comportamiento

\footnotetext{
${ }^{8}$ Para poder comparar los datos de ocupación en las empresas de economía social extraídos de la encuesta, donde se computa a los individuos según el lugar de localización de la empresa, con los datos de ocupación del conjunto de la economía ofrecidos por el Censo de Población de 2001, donde se categoriza a los individuos según su lugar de residencia, se mantiene la hipótesis de que las diferencias entre el lugar de residencia de las personas y su lugar de trabajo no son muy amplias y, en todo caso, que aquéllas tienden a compensarse al contabilizar globalmente los municipios más rurales y los intermedios. Por otra parte, es necesario apuntar que los datos ofrecidos por el Censo de Población de 2001 son los únicos datos desagregados municipalmente y por sexos disponibles para analizar variables referidas al mercado laboral de la región.
} 
diferenciales entre sexos y que tienden a percibirse como "normales". Este factor sociocultural afectaría tanto a la esfera empresarial capitalista como a las empresas de la economía social, por tanto ambos tipos de organizaciones se encuentran inmersas en la misma realidad económica y social. Sin embargo, este hecho resulta contradictorio, por tanto las entidades de economía social han de ser sensibles con los problemas y necesidades sociales (Apelqvist, 1996), lo que conduce a reivindicar una mayor atención y apoyo a la situación laboral de las mujeres por parte de este sector. Adicionalmente, varios autores señalan que la diversidad de género constituye una estrategia innovadora dentro de las empresas para hacer frente a las nuevas exigencias laborales y que la mayor participación femenina refuerza el poder democrático de este tipo de organizaciones (Barberá, 2004; Fregidou-Malama, 2004).

En lo que hace referencia a la participación de las mujeres rurales en los diferentes tipos de empresas de economía social, dentro del ámbito de los municipios más pequeños (menos de 2.000 habitantes), el 64,5\% estaban ocupadas en cooperativas, el $27,7 \%$ en sociedades laborales y el 7,8\% restante en los centros especiales de empleo. Dentro de las distintas clases de cooperativas, las más feminizadas son las cooperativas de trabajo, seguidas de las agrarias y de las de explotación comunitaria de la tierra y/o del ganado, ocupando al 94,5\% de las mujeres en conjunto. Esta situación difiere en orden de relevancia cuantitativa a la de los hombres, ya que el mayor número de ocupados se encuentra en las cooperativas de explotación comunitaria de la tierra, seguido de las agrarias y de las de trabajo. Atendiendo a lo que ocurre en los municipios intermedios, la ocupación femenina en cooperativas disminuye hasta el 51,1\% y toman mayor protagonismo relativo las sociedades laborales, con un $31,1 \%$ de ocupación femenina, y los centros especiales de empleo, con el 17,8\%.

$\mathrm{Al}$ respecto, se ha señalado que la desigual distribución de las propias mujeres dentro de las diversas categorías de empresas de economía social consideradas cabe explicarlas por las distintas características de cada una de ellas (Ribas y Sajardo, 2005). Las mujeres aprecian ciertas particularidades de las cooperativas, tales como la interrelación, participación y proximidad entre los socios, lo que redunda en una mayor implicación entre los socios, a diferencia de otras estructuras empresariales más jerarquizadas como puede ser el caso de las sociedades laborales (Apelqvist, 1996).

REVESCO No 105 - MONOGRÁFICO: La economía social y la igualdad de género -

ISSN: 1885-8031 - www.ucm.es/info/revesco 
Tabla 5: Estimación de la población ocupada por sexo y nivel de ruralidad en la economía social de Castilla y León, 2006

\begin{tabular}{|l|cc|c|c|cc|}
\hline \multirow{2}{*}{ Total cooperativas } & \multicolumn{2}{|c|}{$\begin{array}{c}\text { Municipios menores de } \\
\mathbf{2 . 0 0 0} \text { habitantes }\end{array}$} & \multicolumn{2}{c|}{$\begin{array}{c}\text { Municipios entre 2.000 y } \\
\mathbf{1 0 . 0 0 0} \text { habitantes }\end{array}$} & Total Castilla y León \\
\cline { 2 - 7 } & Mujeres & Varones & Mujeres & Varones & Mujeres & Varones \\
\hline Agraria & 962 & 2.962 & 768 & 1.050 & 3.352 & 8.242 \\
Trabajo & 251 & 844 & 112 & 211 & 510 & 2.004 \\
Explot. com. tierra y/o ganado & 424 & 726 & 616 & 294 & 2.089 & 2.723 \\
Consumidores y usuarios & 234 & 1.278 & 34 & 538 & 290 & 1.990 \\
Enseñanza & 3 & 5 & 0 & 0 & 4 & 8 \\
Transportista & 0 & 0 & 0 & 0 & 18 & 11 \\
Servicios & 3 & 33 & 0 & 0 & 17 & 145 \\
Vivienda & 20 & 29 & 0 & 0 & 36 & 182 \\
Crédito & 0 & 0 & 0 & 0 & 17 & 30 \\
Segundo grado & 2 & 5 & 0 & 0 & 326 & 941 \\
\hline Sociedades Laborales & 26 & 42 & 5 & 7 & 45 & 207 \\
\hline Centros Especiales de Empleo & 414 & 849 & 467 & 1.033 & 2.493 & 4.730 \\
\hline TOTAL & 116 & 165 & 268 & 405 & 1.241 & 2.032 \\
\hline
\end{tabular}

\subsection{Estructura societaria}

Si se analiza la estructura societaria de las empresas de economía social (Gráfico 1), también se aprecia cierta descompensación según el sexo en todos los ámbitos territoriales considerados. Así, del total de socios en este tipo de empresas en los municipios rurales de menos de 2.000 habitantes, tan solo el 19,5\% son mujeres (la media regional es del 26,9\%). Al comparar estos resultados con el porcentaje de mujeres empresarias en el total de los sectores de la economía (Censo de Población de 2001), la proporción es muy similar, pues en estos municipios más pequeños el 20,5\% del total de empresarios eran mujeres. En las zonas rurales intermedias, la proporción de mujeres entre los socios en empresas de economía social desciende hasta el 14,0\%. En este caso, la diferencia con respecto al porcentaje de mujeres empresarias en el conjunto de la economía regional es más clara, ya que la proporción es del $26,5 \%$ para estos municipios.

Distinguiendo entre los socios trabajadores y los que no lo son, se constata mayor representación femenina con respecto a los varones en la primera de las categorías societarias señaladas, sobre todo en el caso de los núcleos intermedios de población. Este resultado puede estar relacionado con la proliferación de cooperativas agrarias en los municipios rurales, en las que existen una cantidad de agricultores socios, mayoritariamente de sexo masculino, que 
se benefician de los servicios de la actividad de la cooperativa particularmente en cuanto a las ventajas que se derivan de la comercialización conjunta, el uso de servicios comunes, etc., pero que no son empleados de dichas cooperativas.

\section{Gráfico 1}

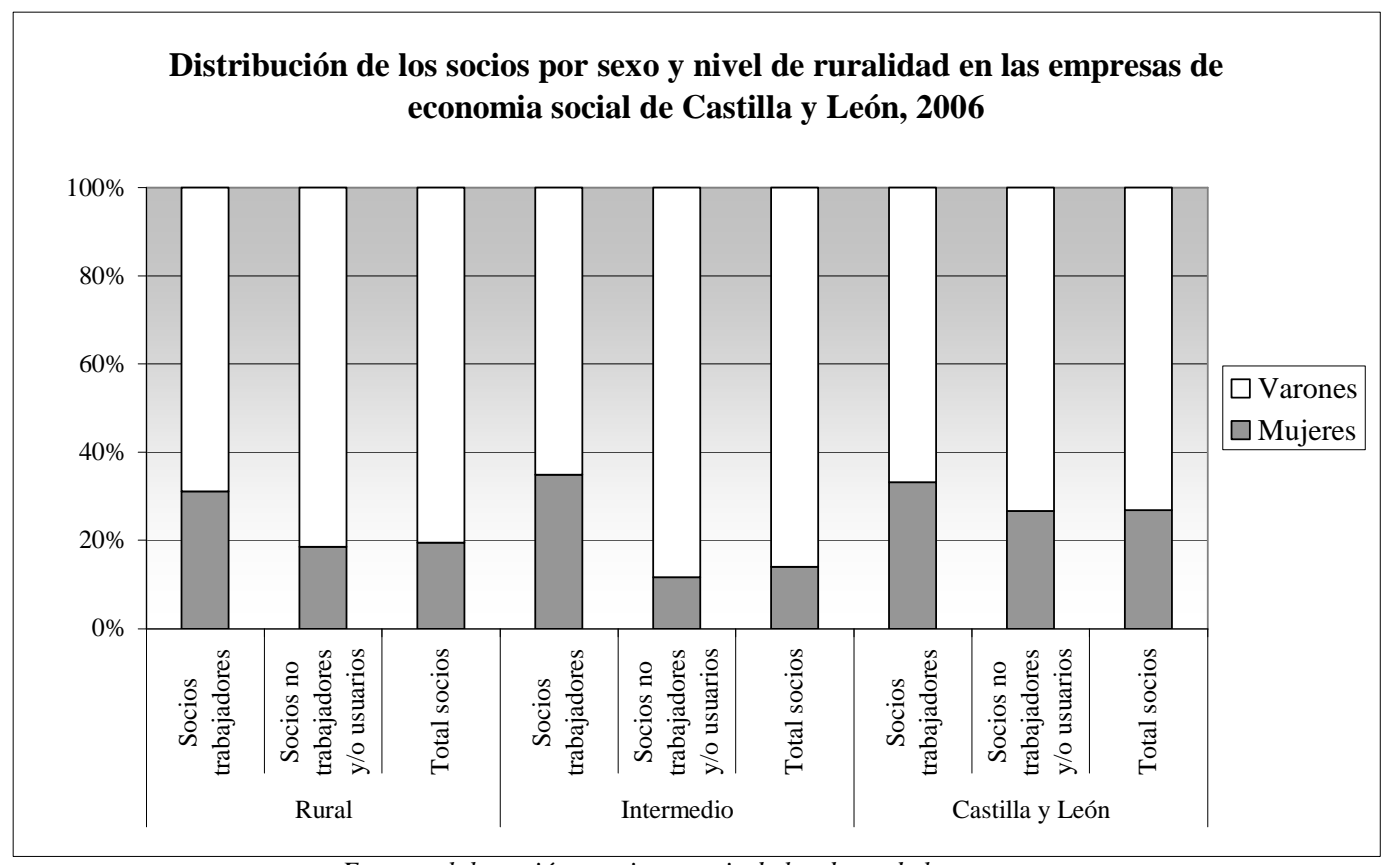

Fuente: elaboración propia a partir de los datos de la encuesta.

El Gráfico 2 muestra la distribución de las mujeres que ostentan la condición de socio dentro de los distintos tipos de entidades de economía social correspondiente a los municipios de menos de 2.000 habitantes. Se comprueba que casi la mitad de las mujeres socias $(49,2 \%)$ lo son de cooperativas agrarias, seguido de las cooperativas de explotación comunitaria de la tierra y/o del ganado, estas últimas con un $26,6 \%$ de las socias. A un nivel inferior se encuentran las sociedades laborales, las cooperativas de crédito y las cooperativas de trabajo. La presencia de mujeres socias resulta testimonial en las cooperativas de consumidores y usuarios, así como en el grupo que conforman las cooperativas de segundo grado.

REVESCO No 105 - MONOGRÁFICO: La economía social y la igualdad de género -

ISSN: 1885-8031 - www.ucm.es/info/revesco 


\section{Gráfico 2}

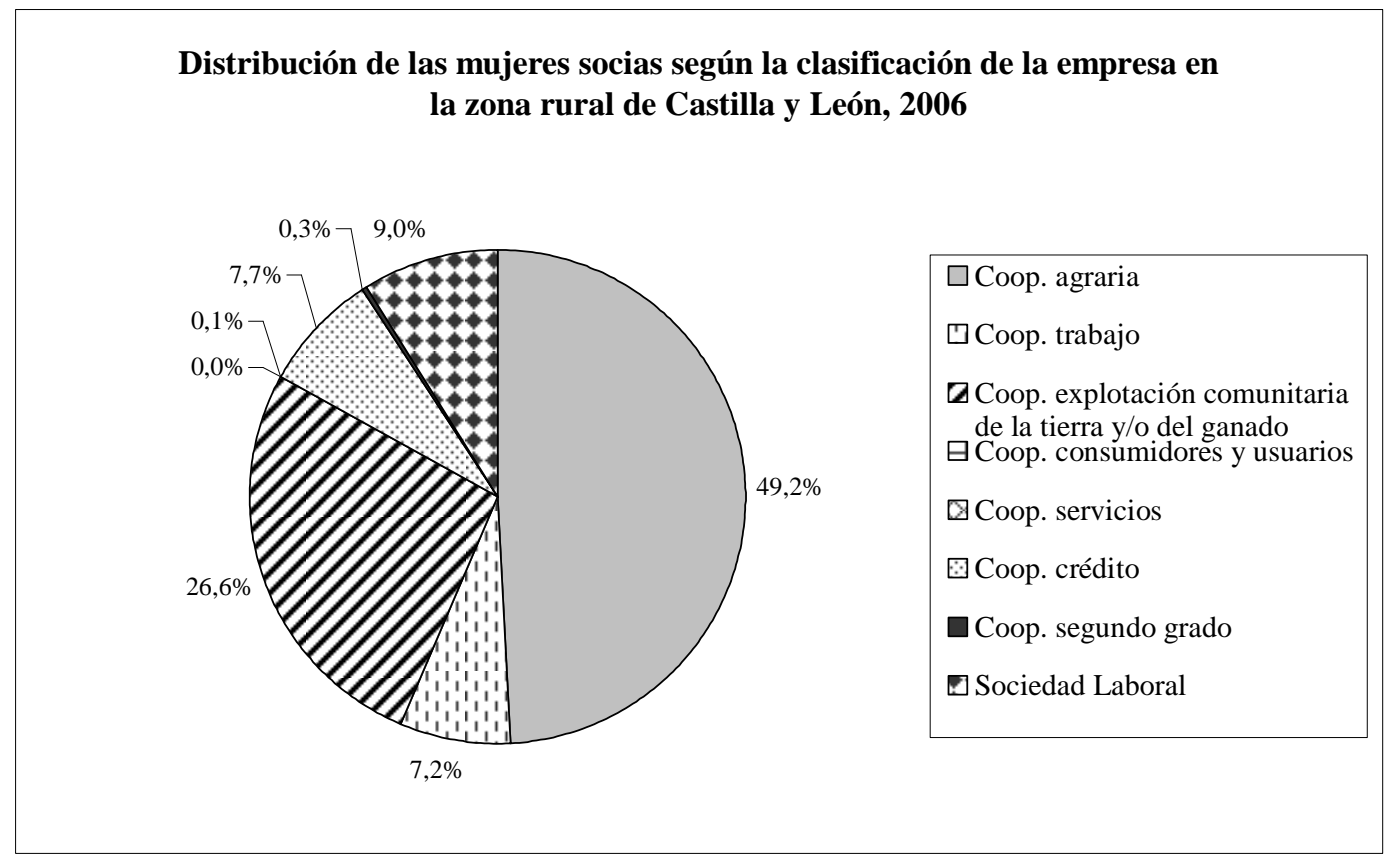

Fuente: elaboración propia a partir de los datos de la encuesta.

Analizando los datos extraídos en la encuesta, acerca de la distribución de las mujeres socias en los diferentes tipo de empresas y diferenciando si son o no socias trabajadoras, se comprueba que solo el $1,7 \%$ de las socias de cooperativas agrarias tienen la condición de socias trabajadoras y que el 9,6\% de las socias trabajan en las cooperativas de explotación comunitaria de la tierra y/o del ganado. Por su parte, en las cooperativas de trabajo y en las de servicios existe un porcentaje de socias trabajadoras que alcanza el 83,8\% y el 50\%, respectivamente. Nuevamente, este hecho puede ser el resultado de la naturaleza y especiales características de las cooperativas agrarias y de explotación de la tierra, de forma que no es frecuente que las socias sean a su vez trabajadoras dentro de dicho tipo de organizaciones.

\subsection{Personal empleado}

En lo que concierne a los empleados en las empresas de economía social de la región, si se analizan las características del empleo según la temporalidad y se compara según sexo (Tabla 6), se puede comprobar la mayor eventualidad que experimenta el colectivo de mujeres con respecto a los varones, sea cual sea el ámbito territorial considerado. De este modo, en la citada Tabla puede constatarse que el 38,6\% de las mujeres que trabajan en cooperativas y sociedades laborales en los municipios rurales de la región lo hacen por medio de contratos eventuales, por un 34,2\% en el caso de los varones. Esta diferencia es más acusada en el caso REVESCO No 105 - MONOGRÁFICO: La economía social y la igualdad de género -

ISSN: 1885-8031 - www.ucm.es/info/revesco 
de los municipios intermedios, donde la temporalidad femenina en este tipo de entidades alcanza el 40,7\%, mientras que la masculina representa prácticamente la mitad, un 24,8\%.

Si a continuación se comparan estos datos con lo acontecido en el conjunto de empresas de la economía rural regional (tanto las de economía social como las convencionales), según el Censo de Población de 2001 se comprueba que la temporalidad del conjunto de empleadas rurales asciende al 41,2\% y en las zonas intermedias al 39,9\%. De ello se desprende, por tanto, que las mujeres rurales que trabajan en las empresas de economía social tienen una eventualidad inferior en sus contratos a la que se observa entre las del conjunto de la economía rural, si bien la diferencia no es muy amplia (Ribas, 2005).

Diferenciando según tipos de empresas de economía social, a escala regional no se aprecian brechas significantes en el grado de temporalidad de las mujeres, ya que tanto en cooperativas como en sociedades laborales los contratos temporales femeninos se sitúan en torno al 36\%. En cambio, en las zonas rurales se detecta una mayor eventualidad femenina en las cooperativas $(41,7 \%)$ con respecto a las sociedades laborales $(28,2 \%)$. En los municipios intermedios tal brecha es de menor magnitud, con una temporalidad de las mujeres que trabajan en cooperativas que supera en tres puntos porcentuales a lo que ocurre en las sociedades laborales.

Aunque no se dispone de datos propios referidos a la proporción de mujeres dentro de los puestos de dirección en empresas de economía social, son varios los estudios que han puesto de manifiesto las mayores cuotas de poder que ostentan los varones, si bien este hecho es de menor relevancia cuando se compara con lo acontecido en el caso de las entidades mercantiles. Así, por ejemplo, según el estudio de COCETA (2004) para las cooperativas de trabajo asociado en España, en este tipo de entidades la responsabilidad es ostentada por un varón en el 60,2\% de los casos. Por su parte, Ribas (2005) apunta que la presencia de las mujeres en los consejos rectores de las cooperativas mixtas de la Comunidad de Madrid alcanza tan solo el 35\%, mientras que en el caso de la Comunidad Valenciana las mujeres participan con un porcentaje del $27,5 \%$ en los consejos rectores de las cooperativas de trabajo asociado de dicha región. Finalmente, en el reciente estudio de Esteban et al. (2010), se destaca que de las personas que forman parte de los consejos rectores de las cooperativas de la

REVESCO No 105 - MONOGRÁFICO: La economía social y la igualdad de género -

ISSN: 1885-8031 - www.ucm.es/info/revesco 
provincia de Teruel, tan solo el 17,09\% son mujeres, un promedio algo superior al que se registra en las empresas lucrativas.

Tabla 6: Distribución de los empleados (\%) por sexo y nivel de ruralidad en la economía social de Castilla y León, 2006

\begin{tabular}{|c|c|c|c|c|c|}
\hline & & \multicolumn{2}{|c|}{ Mujeres } & \multicolumn{2}{|c|}{ Varones } \\
\hline & & $\begin{array}{l}\text { Empleados } \\
\text { indefinidos }\end{array}$ & $\begin{array}{l}\text { Empleados } \\
\text { temporales }\end{array}$ & $\begin{array}{l}\text { Empleados } \\
\text { indefinidos }\end{array}$ & $\begin{array}{l}\text { Empleados } \\
\text { temporales }\end{array}$ \\
\hline \multirow{3}{*}{$\begin{array}{c}\text { Municipios } \\
\text { rurales }\end{array}$} & Cooperativa & 58,3 & 41,7 & 71,6 & 28,4 \\
\hline & Sociedad Laboral & 71,8 & 28,2 & 48,0 & 52,0 \\
\hline & Total & 61,4 & 38,6 & 65,8 & 34,2 \\
\hline \multirow{3}{*}{$\begin{array}{l}\text { Municipios } \\
\text { intermedios }\end{array}$} & Cooperativa & 58,2 & 41,8 & 82,8 & 17,2 \\
\hline & Sociedad Laboral & 61,6 & 38,4 & 60,0 & 40,0 \\
\hline & Total & 59,3 & 40,7 & 75,2 & 24,8 \\
\hline \multirow{3}{*}{$\begin{array}{l}\text { Castilla y } \\
\text { León }\end{array}$} & Cooperativa & 63,6 & 36,4 & 78,6 & 21,4 \\
\hline & Sociedad Laboral & 63,3 & 36,7 & 52,0 & 48,0 \\
\hline & Total & 63,6 & 36,4 & 72,6 & 27,4 \\
\hline
\end{tabular}

\section{CONCLUSIONES}

En las últimas décadas, tanto desde los ámbitos supranacional como nacional y regional, se están aplicando medidas de acción para tratar de conseguir reducir las desigualdades socioeconómicas existentes entre sexos, a fin de procurar una sociedad más justa y solidaria. Una parte importante de estas medidas están en consonancia con los aspectos normativos (principios y valores) de la economía social, concretados en una participación igualitaria, la solidaridad y la democracia. En este sentido, dentro del contenido normativo e instrumental de los diversos planes de igualdad de oportunidades impulsados desde distintos organismos públicos, se han identificado programas y actuaciones que, de forma tácita o expresa, vinculan sus resultados a las actividades del sector de la economía social, ya sea en su vertiente empresarial o en su vertiente social sin fines de lucro. Al respecto, cabe destacar en particular las medidas y actuaciones tendentes a mejorar la integración laboral de las mujeres, tanto como empresarias como asalariadas, a potenciar su participación en los órganos de decisión sociales y políticos, a mejorar la compatibilidad de la vida familiar y profesional, o las orientadas a frenar la despoblación en las zonas rurales.

REVESCO No 105 - MONOGRÁFICO: La economía social y la igualdad de género -

ISSN: 1885-8031 - www.ucm.es/info/revesco 
Uno de los cambios sociales más profundos a los que estamos asistiendo en los últimos años tiene que ver, precisamente, con el creciente desequilibrio socioeconómico territorial entre las zonas rurales y las zonas urbanas, sobre todo en algunas regiones del interior español. Así, Castilla y León es la Comunidad Autónoma cuyo medio rural más se ha despoblado en las últimas décadas, quedando configurado actualmente por un elevado número de municipios rurales altamente envejecidos y en declive social y económico. Para tratar de impulsar la reactivación económica y social de estas zonas rurales, la literatura económica y las políticas públicas instrumentadas consideran un elemento fundamental potenciar la contribución de las mujeres rurales, poniendo en marcha planes y estrategias que promueven apoyos a este colectivo, tratando de incidir y hacer frente a sus especiales dificultades.

Y, en este contexto, la economía social representa un sector capaz de impulsar el desarrollo del medio rural y de mejorar la situación laboral de las mujeres que habitan en él. Así, la economía social engloba un tipo de organizaciones que resultan eficaces para aprovechar los nuevos yacimientos de empleo y los recursos endógenos que promuevan el desarrollo regional y local, contribuyendo a diversificar la economía rural y a dotarla de una mayor capacidad de generación de trabajo y renta que frenaría el retroceso demográfico.

El análisis de la participación de las mujeres en las entidades de la economía social del medio rural castellano y leonés ha puesto de manifiesto, no obstante, que también en este sector persisten las desigualdades por razón de sexo en cuanto a la contribución relativa de hombres y mujeres en este tipo de actividades, ya sea como empleados o como socios, así como también en cuanto a la temporalidad del empleo. Además, estas desigualdades no difieren de manera significativa de las que se observan dentro del conjunto de la economía rural de la región. Estos resultados vienen a poner de manifiesto que, si bien las entidades de economía social se apoyan en principios que fomentan un alto grado de compromiso de la organización en favor de la equidad de género, lo que hace de ellas unas organizaciones particularmente interesantes para favorecer la consecución del objetivo de la igualdad de oportunidades, en la práctica dicha cualidad no se está manifestando suficientemente o al menos en la medida que cabría esperar. Esta circunstancia permite constatar, en última instancia, la existencia de una cierta separación entre los aspectos normativos que deben

REVESCO No 105 - MONOGRÁFICO: La economía social y la igualdad de género -

ISSN: 1885-8031 - www.ucm.es/info/revesco 
orientar el funcionamiento de las organizaciones de la economía social y lo que constituye la realidad de su actividad.

Surge, asimismo, la necesidad de profundizar en la investigación acerca de las características diferenciales que presenta la situación laboral de hombres y mujeres en el ámbito de las diversas entidades de economía social, el análisis de sus causas y de posibles vías de actuación. Los resultados de este tipo de estudios tienen especial relevancia para las zonas rurales, por cuanto las diferencias por razón de sexo son mayores y el desarrollo socioeconómico depende en buena medida de que las mujeres puedan ver mejor cubiertas sus expectativas laborales y de calidad de vida.

\section{BIBLIOGRAFÍA}

APELQVIST, Katerina. Estrategias para una autoridad compartida entre hombres y mujeres en las cooperativas. Revista de Cooperación Internacional, nº 1, 1996, p. 35-47.

BARBERÁ HEREDIA, Ester. Diversidad de género, igualdad de oportunidades y entornos laborales (La diversidad de género como estrategia favorecedora de la igualdad de oportunidades en los entornos laborales). CIRIEC-España, Revista de Economía Pública, Social y Cooperativa, $\mathrm{n}^{\mathrm{o}}$ 50, 2004, p. 37-53.

BAREA, José y MONZÓN, José Luís. La economía social en España en el año 2000. Valencia: CIRIEC-España, 2002. 551 p.

BEL DURÁN, Paloma. Las empresas de economía social y la política de desarrollo rural. En: CHAVES ÁVILA, Rafael (dir.). La economía social en las políticas públicas en España. Valencia: CIRIEC-España, 2007. 312 p.

CAMARERO RIOJA, Luís Alfonso (coord.). El trabajo desvelado. Trayectorias ocupacionales de las mujeres rurales en España. Madrid: Instituto de la Mujer, 2006. 190 p.

CAMARERO RIOJA, Luís Alfonso y SAMPEDRO GALLEGO, Rosario. “¿Por qué se van las mujeres? El continuum de movilidad como hipótesis explicativa de la masculinización rural. Revista Española de Investigaciones Sociológicas, n 124, 2008, p. 73-105.

CASTAÑO COLLADO, Cecilia (coord.). Indicadores laborales básicos de la situación de la mujer en España y sus regiones. Madrid: Instituto de la Mujer, 2004. 291 p.

REVESCO No 105 - MONOGRÁFICO: La economía social y la igualdad de género -

ISSN: 1885-8031 - www.ucm.es/info/revesco 
CHAVES ÁVILA, Rafael, RIBAS BONET, María Antonia y SAJARDO MORENO, Antonia. Cumplimiento del primer principio: análisis de la discriminación por género en las cooperativas españolas. Revista de la Cooperación Internacional, nº 1, 2005, p. 101118.

CHAVES ÁVILA, Rafael y MONZÓN, José Luís. Economía social y sector no lucrativo: actualidad científica y perspectivas. CIRIEC-España, Revista de Economía Pública, Social y Cooperativa, $\mathrm{n}^{\circ}$ 37, 2001, p. 7-33.

CHAVES ÁVILA, Rafael y MONZÓN, José Luís. Panorama de la investigación en Economía Social. Estudios de Economía Aplicada, Vol. ${ }^{\circ}$ 26-1, 2008, p. $29-56$.

CONFEDERACIÓN ESPAÑOLA DE COOPERATIVAS DE TRABAJO ASOCIADO (COCETA). Estudio sobre la realidad social y laboral de las mujeres en el cooperativismo de trabajo asociado en España. Madrid: COCETA, 2004. 93 p.

COMISIÓN EUROPEA. Plan de Trabajo para la Igualdad entre las mujeres y los hombres (2006-2010). Bruselas: COM(2006) 92 final, 2006. 23 p.

CONSEJO ECONÓMICO Y SOCIAL (CES) DE CASTILLA Y LEÓN. Las mujeres en el medio rural de Castilla y León. Valladolid: Informe a Iniciativa Propia, 2004. 340 p.

DE CABO, Gema y GARZÓN, Ma José. Diferencia y discriminación salarial por razón de sexo. Madrid: Instituto de la Mujer, 2007. 285 p.

ESTEBAN, Ma Luisa, GARGALLO, Ana y PÉREZ, Francisco Javier. Composición del consejo rector y género en las cooperativas turolenses. Revesco Revista de Estudios Cooperativos, $\mathrm{n}^{\circ} 101,2010$, p. 7-27.

FERNÁNDEZ ARUFE, Josefa Eugenia y GÓMEZ GARCÍA, Jesús Mª (dirs.). La economía social en Castilla y León. Valladolid: Junta de Castilla y León, 2007. 199 p.

FERNÁNDEZ ARUFE, Josefa Eugenia y GÓMEZ GARCÍA, Jesús Ma y ROMÁN ORTEGA, Azucena (coords.). Estudios de economía social. Valladolid: Departamento de Economía Aplicada, Universidad de Valladolid, 2010. 431 p.

FREGIDOU MALAMA, María. ¿Es necesario equilibrar el poder en las cooperativas entre mujeres y hombres?. CIRIEC-España, Revista de Economía Pública, Social y Cooperativa, nº 50, 2004, p. 151-163.

GARCÍA PASCUAL, Francisco. (coord.). El mundo rural en la era de la globalización. Madrid: Ministerio de Agricultura, Pesca y Alimentación, 2001. 514 p.

REVESCO No 105 - MONOGRÁFICO: La economía social y la igualdad de género -

ISSN: 1885-8031 - www.ucm.es/info/revesco 
GARCÍA RAMÓN, Ma Dolores y BAYLINA, Mireia (eds.). El nuevo papel de las mujeres en el desarrollo rural. Barcelona: Ed. Oikos-tau, 2000. 336 p.

GARCÍA SANZ, Benjamín. La mujer rural ante el reto de la modernización de la sociedad rural. Madrid: Instituto de la Mujer, 2004. 335 p.

GARRIDO, Alicia, ALVARO, José Luís, AGULlÓ, Mª Silveria y PALOMERO, Coral. Las mujeres jóvenes y el trabajo. Madrid: Instituto de la Mujer, 2006. 159 p.

GÓMEZ GARCÍA, Jesús Mª y ROMÁN ORTEGA, Azucena. La economía social y su contribución a la promoción del desarrollo local y regional. Revista Universitaria de Ciencias del Trabajo, $\mathrm{n}^{\circ}$ 6, 2007, p. 727-753.

GONZÁLEZ REGIDOR, Jesús (coord.). Desarrollo rural sostenible: un nuevo desafío. Madrid: Ministerio de Agricultura, Pesca y Alimentación, 2008. 214 p.

JUNTA DE CASTILLA Y LEÓN. IV Plan de Igualdad entre mujeres y hombres 2007-2011. Valladolid: Consejería de Familia e Igualdad de Oportunidades, 2007. 80 p.

LANGREO NAVARRO, Alicia y BENITO GARCÍA, Isabel. La mujer en la agricultura y en el medio rural. En: FUNDACIÓN DE ESTUDIOS RURALES. Agricultura Familiar en España 2005. Madrid: Fundación de Estudios Rurales, 2005. 346 p.

MELIÁN NAVARRO, Amparo y CAMPOS CLIMENT, Vanesa. Emprendedurismo y economía social como mecanismos de inserción sociolaboral en tiempos de crisis. Revesco Revista de Estudios Cooperativos, $\mathrm{n}^{\circ}$ 100, 2010, p. 43-67.

MINISTERIO DE AGRICULTURA, PESCA Y ALIMENTACIÓN. Plan de Igualdad entre mujeres y hombres en el medio rural. Madrid: Ministerio de Agricultura, Pesca y Alimentación, 2007. 76 p.

MINISTERIO DE IGUALDAD. Plan Estratégico de Igualdad de Oportunidades 2008-2011. Madrid: Ministerio de Igualdad, 2007. 115 p.

MONZÓN, José Luís. Economía social y conceptos afines: fronteras borrosas y ambigüedades conceptuales del Tercer Sector. CIRIEC-España, Revista de Economía Pública, Social y Cooperativa, no 56, 2006, p. 9-24.

PUENTES POYATOS, Raquel y VELASCO GÁMEZ, Ma del Mar. Importancia de las sociedades cooperativas como medio para contribuir al desarrollo económico, social y medioambiental, de forma sostenible y responsable. Revesco Revista de Estudios

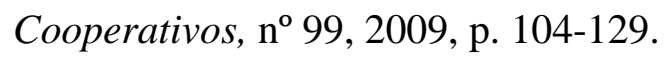

REVESCO No 105 - MONOGRÁFICO: La economía social y la igualdad de género -

ISSN: 1885-8031 - www.ucm.es/info/revesco 
RIBAS BONET, $\mathrm{M}^{\mathrm{a}}$ Antonia. Mujer y trabajo en la economía social. Madrid: Consejo Económico y Social, 2005. 283 p.

RIBAS BONET, Ma Antonia y SAJARDO MORENO, Antonia. La desigual participación de hombres y mujeres en la economía social: teorías explicativas. CIRIEC-España, Revista de Economía Pública, Social y Cooperativa, nº 50, 2004, p. 77-103.

RIBAS BONET, Ma Antonia y SAJARDO MORENO, Antonia. La diferente participación laboral de las mujeres entre las cooperativas y las sociedades laborales. CIRIEC-España, Revista de Economía Pública, Social y Cooperativa, nº 52, 2005, p. 267-278.

RICO GONZÁLEZ, Margarita y FRANCO JUBETE, Fernando. Las perspectivas de futuro de las mujeres del medio rural de Castilla y León. En: FUNDACIÓN ENCUENTRO. Informe España 2009. Madrid: Fundación Encuentro, 2009. 422 p.

RICO GONZÁLEZ, Margarita y GÓMEZ GARCÍA, Jesús Mª La contribución de la mujer en la economía rural de Castilla y León. Revista de Economía Agraria y Recursos Naturales, $\mathrm{n}^{\circ}$ 18, 2009, p. 51-77.

RICO GONZÁLEZ, Margarita y GÓMEZ-LIMÓN, José Antonio. Propuesta metodológica para la construcción de indicadores sintéticos de igualdad de género. El caso del medio rural de Castilla y León. Revista Internacional de Sociología, [on line], doi: 10.3989/ris.2009.04.27.

SALINAS RAMOS, Francisco y HERRANZ DE LA CASA, José María (coords.). La economía social, instrumento de cohesión y empleo en Castilla y León. Ávila: Universidad Católica de Ávila, 2007. 305 p.

SAMPEDRO GALLEGO, Rosario. Género y ruralidad. Las mujeres ante el reto de la desagrarización. Madrid: Ministerio de Trabajo y Asuntos Sociales, 1996. 544 p.

SÁNCHEZ SOLANO, Enrique. El autoempleo femenino en la economía social. En: SALINAS RAMOS, Francisco y HERRANZ DE LA CASA, José María (coords.). Empresas de economía social: aspectos para su desarrollo. Ávila: Universidad Católica de Ávila, 2007. 222 p.

SERRA YOLDI, Inmaculada. Las políticas públicas de igualdad en el empleo y la economía social y cooperativa. CIRIEC-España, Revista de Economía Pública, Social y Cooperativa, $\mathrm{n}^{\circ}$ 50, 2004, p. 105-122.

REVESCO No 105 - MONOGRÁFICO: La economía social y la igualdad de género -

ISSN: 1885-8031 - www.ucm.es/info/revesco 